\title{
Effects of Doxycycline on Production of Growth Factors and Matrix Metalloproteinases in Pulmonary Fibrosis
}

\author{
Hanako Fujita ${ }^{a}$ Noriho Sakamoto ${ }^{a}$ Yuji Ishimatsu ${ }^{a}$ Tomoyuki Kakugawa ${ }^{a}$ \\ Shintaro Hara ${ }^{a}$ Atsuko Hara ${ }^{a}$ Misato Amenomori ${ }^{a}$ Hiroshi Ishimoto $^{b}$ \\ Towako Nagata $^{a}$ Hiroshi Mukae $^{b}$ Shigeru Kohno ${ }^{a}$ \\ ${ }^{a}$ Second Department of Internal Medicine, Nagasaki University School of Medicine, Nagasaki, and bepartment of \\ Respiratory Medicine, University of Occupational and Environmental Health, Fukuoka, Japan
}

\section{Key Words}

Alveolar epithelial cells - Connective tissue growth factor • Epithelial mesenchymal transition · Fibroblast $\cdot$ Smad

\begin{abstract}
Background: Idiopathic pulmonary fibrosis (IPF) is characterized by progressive fibrosis and a poor prognosis. Alveolar epithelial cells (AECs) are considered to play important roles by releasing growth factors and matrix metalloproteinases (MMPs) and by being involved in epithelial mesenchymal transition in IPF. Doxycycline hydrochloride (DOXY), an inhibitor of MMPs, attenuates pulmonary fibrosis in models and in patients with IPF; however, the mechanism of this action remains obscure. Objectives: The present study investigated the effect of DOXY on growth factors and MMP production in AECs. Methods: Bleomycin (BL)-induced murine pulmonary fibrosis was treated with DOXY and examined by pathological and immunohistochemical staining. The human alveolar epithelial cell line A549 was stimulated with transforming growth factor (TGF)- $\beta 1$ and incubated with DOXY, and then the expression of growth factors, MMPs, and collagen type I was evaluated at the mRNA and protein lev-
\end{abstract}

els. We also evaluated the effects of DOXY on the TGF- $\beta 1$ induced Smad signaling pathway. Results: DOXY reduced fibrosis scores and the production of collagen type I, connective tissue growth factor (CTGF), and TGF- $\beta 1$ in BL models. DOXY inhibited the mRNA expression of MMP-2, MPP-9, CTGF, and collagen type I as well as the production of MMP2 and platelet-derived growth factor-AA protein induced in A549 cells by TGF- $\beta 1$ but not by Smad 2 and Smad3 phosphorylation. We did not find a similar effect of DOXY in normal lung fibroblasts. Conclusions: Our results suggest that DOXY could be useful for attenuating pulmonary fibrosis through the inhibition of growth factors and MMP production in AECs.

Copyright $\odot 2011$ S. Karger AG, Basel

\section{Introduction}

Idiopathic pulmonary fibrosis (IPF) is the most common progressive and lethal pulmonary fibrotic disorder, but its etiology is unknown. The pathogenesis of IPF was originally thought to involve lung damage of unknown origin that produced an inflammatory response leading

\section{KARGER}

Fax +41613061234

E-Mail karger@karger.ch

www.karger.com
C 2011 S. Karger AG, Basel

$0025-7931 / 11 / 0815-0420 \$ 38.00 / 0$

Accessible online at:

www.karger.com/res
Noriho Sakamoto, MD, $\mathrm{PhD}$

Second Department of Internal Medicine

Nagasaki University School of Medicine

1-7-1 Sakamoto, Nagasaki 852-8501 (Japan)

Tel. +81 95819 7273, E-Mail nsakamot@ nagasaki-u.ac.jp 
to fibrosis. However, recent findings suggest that epithelial cell damage is the initial event that triggers a series of repair pathways that are in some way aberrant and lead to inappropriate fibrosis [1]. During this process of pulmonary fibrosis, epithelial damage causes the consecutive release of several fibrotic mediators including growth factors such as transforming growth factor (TGF)- $\beta$, platelet-derived growth factor (PDGF), connective tissue growth factor (CTGF), and hepatocyte growth factor (HGF) as well as metalloproteinases (MMPs). These mediators provoke the migration, proliferation, and activation of mesenchymal cells with the formation of active fibroblastic/myofibroblastic foci, leading to the exaggerated accumulation of extracellular matrix (ECM) that mirrors abnormal wound repair [2]. Alveolar epithelial cells (AECs) apparently serve as progenitor cells that can undergo differentiation to fibroblasts/myofibroblasts in the presence of TGF- $\beta[3,4]$. This process is called epithelial mesenchymal transition (EMT) and could regulate pulmonary fibrosis.

Doxycycline hydrochloride (DOXY) is a tetracycline antibiotic that inhibits bacterial protein synthesis and exerts anti-inflammatory effects as well as apoptosis [5-7]. DOXY also inhibits MMPs and thus has been widely applied to treat aneurysms [8], periodontal disease [9], cancer, bone metastasis [10], and pleurodesis. The mechanisms of MMP inhibition by DOXY are not yet completely understood, but DOXY binds directly to the active target site of MMPs and induces degradation of the proMMP zymogen or provokes the inhibition of MMP mRNA transcription [11]. In the bleomycin (BL)-induced model of pulmonary fibrosis, DOXY attenuates fibrosis through MMP inhibition [12], which leads to the notion that preventing MMP activity could be of therapeutic benefit to patients with IPF. The results of a recent small open trial of such patients indicate that long-term DOXY administration might be a candidate therapeutic regimen [13]. However, the definitive mechanism of DOXY with respect to pulmonary fibrosis and its specific effects on alveolar epithelial cells in pulmonary fibrosis remain obscure.

We evaluated the effect of DOXY on the BL-induced pulmonary fibrosis model in vivo and on TGF- $\beta 1$-induced growth factors and ECM production in the AECs and fibroblasts that are relevant to the progression of lung fibrosis in vitro. We also examined the Smad signaling pathway to clarify the mechanism of DOXY in the production of TGF- $\beta 1$-induced mediators.

Effects of Doxycycline on Pulmonary Fibrosis

\section{Materials and Methods}

\section{Animals}

Nine-week-old male Institute for Cancer Research (ICR)-specific pathogen-free mice (Charles River Japan, Inc., Yokohama, Japan) weighing about $35 \mathrm{~g}$ were maintained under standard conditions with free access to drinking water and pelleted food at the Division of Comparative Medicine, Center for Frontier Life Sciences, Nagasaki University, Nagasaki, Japan. The mice were intravenously injected with $10 \mathrm{mg} / \mathrm{kg} / \mathrm{day}$ of BL (Nippon Kayaku, Tokyo, Japan) dissolved ( $2 \mathrm{mg} / \mathrm{ml})$ in isotonic saline (SA) or with SA ( $5 \mathrm{ml} / \mathrm{kg} /$ day) alone for 5 consecutive days [14]. The animals were then orally dosed with either $2 \mathrm{mg} / \mathrm{kg} /$ day of DOXY (Wako Pure Medical Industries, Ltd., Osaka, Japan) in distilled water $(0.35 \mathrm{mg} / \mathrm{ml})$ or with distilled water alone as a control once daily starting the day before or 14 days after being injected intravenously with BL or SA throughout the study. The mice were randomly divided into the following groups: SA with distilled water (control), BL with distilled water (BL), and DOXY 1 day before (pre-DOXY) and 14 days after (post-DOXY) BL injection. The mice were sacrificed and evaluated 14, 42, and 56 days after the start of BL or SA administration. The Ethics Review Committees for Animal Experimentation of Nagasaki University School of Medicine approved the experimental protocol.

\section{Histology and Fibrosis Scores}

At 14,42 , and 56 days after starting BL or SA injections, the mice ( $n=3-5$ per group at each time point) were sacrificed by exsanguination under deep anesthesia (sodium pentobarbital, 50 $\mathrm{mg} / \mathrm{kg}$, i.p.). The left lungs were then removed via a midline incision, fixed in $10 \%$ formaldehyde/neutral buffer, and embedded in paraffin, and then 4-mm sections of embedded tissues were stained with hematoxylin-eosin (HE) and immunohistochemically analyzed. The degree of cellular infiltration and fibrosis was evaluated from 0 (normal) to 8 (most severe) based on mean Ashcroft scores [15] obtained from 25 consecutive microscopic fields that were randomly assessed along the pleura of each section.

\section{Immunohistochemistry}

Sections were conventionally analyzed by avidin-biotin-peroxidase histochemical staining using a Vectastain Elite ABC Kit (Vector Laboratories, Burlingame, Calif., USA) for TGF- $\beta 1$, PDGF-A, PDGF-B, CTGF, MMP-2, MMP-9, and collagen type I. Antigen was retrieved in $10 \mathrm{mM}$ sodium citrate at $\mathrm{pH} 6.0$ using the steamer protocol for TGF- $\beta 1$ or the standard protocol for PDGFB, CTGF, MMP-2, and MMP-9. Antigen retrieval for PDGF-A and for collagen type I proceeded in $10 \mathrm{~mm}$ sodium citrate at $\mathrm{pH}$ 5.5 and with protease $\mathrm{K}$ using the standard protocol, respectively. Endogenous peroxidase activity was quenched by incubation for $20 \mathrm{~min}$ in $0.3 \% \mathrm{H}_{2} \mathrm{O}_{2}$ in absolute methanol. Nonspecific binding was blocked with $1.5 \%$ goat or rabbit serum for $20 \mathrm{~min}$ and then sections were incubated overnight in rabbit TGF- $\beta 1$, PDGF-A, CTGF or collagen type I antibody (Abcam, Inc., Cambridge, Mass., USA), rabbit PDGF-B antibody (Gene Tex, Irvine, Calif., USA) or goat MMP-2 or MMP-9 antibody (Santa Cruz Biotechnology Inc., Santa Cruz, Calif., USA), respectively. The sections were washed with PBS and further processed using the kit according to the manufacturer's instructions. Areas of interest were visualized using 3, 3-diaminobenzidine and $\mathrm{H}_{2} \mathrm{O}_{2}$, and then the sections were counterstained with Mayer's hematoxylin. 


\section{Measurement of Lung Hydroxyproline Content}

We measured the hydroxyproline content in the right lungs of the mice at 14 and 56 days after BL or SA injection $(n=3-5$ in each group) to estimate the total collagen deposition in the lungs as an indicator of pulmonary fibrosis. Wet lungs were weighed, dried, homogenized, and hydrolyzed in $6 \mathrm{~N}$ hydrochloric acid. Hydroxyproline was then analyzed in the supernatant at 348 and $450 \mathrm{~nm}$ using high-performance liquid chromatography (HPLC 800 series; Nippon Bunko, Tokyo, Japan).

\section{Cell Culture and Stimulation}

Human type II alveolar epithelial cells (A549; ATCC, Manassas, Va., USA) and normal human lung fibroblasts (Lonza Japan Ltd., Tokyo, Japan) were maintained in low glucose-F-12 containing 10\% fetal bovine serum (FBS; Life Technologies Corporation, Carlsbad, Calif., USA) or in fibroblast growth medium (FGM)-2 (Lonza Japan), respectively, at $37^{\circ} \mathrm{C}$ in a humidified $5 \% \mathrm{CO}_{2}$ atmosphere. Confluent cells were incubated in serum-free F-12 medium containing $0.1 \%$ bovine serum albumin (BSA) or in FGM-2 for $24 \mathrm{~h}$ before stimulation with recombinant human TGF- $\beta 1$ (R\&D systems, Minneapolis, Minn., USA). A549 cells or fibroblasts were incubated with either various concentrations of TGF$\beta 1$ activated with BSA and $\mathrm{HCl}$ or equal amounts of vehicle. A549 cells were lysed and harvested $3 \mathrm{~h}$ later for reverse transcription (RT) PCR and the supernatants were extracted at $24 \mathrm{~h}$ for ELISA and MMP activity assays. A549 cells were incubated with several concentrations of DOXY from $3 \mathrm{~h}$ before stimulation with $1 \mathrm{ng} /$ $\mathrm{ml}$ TGF- $\beta 1$ until the end of the study. Fibroblasts were stimulated with $5 \mathrm{ng} / \mathrm{ml}$ of TGF- $\beta 1$ with or without DOXY and then lysed and harvested $48 \mathrm{~h}$ later for RT PCR.

\section{RT and Real-Time PCR}

Primers for PDGF-A, PDGF-B, CTGF, HGF, collagen type I, MMP-2, MMP-9, and $\beta$-actin mRNA were included in the TaqMan ${ }^{\circledR}$ Gene Expression Assays (Applied Biosystems, Foster City, Calif., USA). Total RNA was isolated using an RNeasy Plus Mini Kit (Qiagen K.K., Tokyo, Japan) and RT-PCR proceeded using the SuperScript III First Strand Synthesis System (Life Technologies Japan Ltd., Tokyo, Japan). The target was reverse transcribed with initial denaturation at $65^{\circ} \mathrm{C}$ for $5 \mathrm{~min}$ followed by 40 cycles of PCR amplification at $50^{\circ} \mathrm{C}$ for $50 \mathrm{~min}, 85^{\circ} \mathrm{C}$ for $5 \mathrm{~min}$, and $37^{\circ} \mathrm{C}$ for 20 min using GeneAmp PCR System 9700 (Applied Biosystems). The inner control primer was $\beta$-actin. The PCR products were analyzed with 7500 system SDS software (Applied Biosystems).

\section{ELISA and MMP Activity Assays}

Concentrations of PDGF-AA, PDGF-AB, PDGF-BB, HGF (R\&D systems), and CTGF (Antigenix America, Inc., Huntington Station, N.Y., USA) were analyzed in culture media using the appropriate ELISA kit, and those of MMP-2 and MMP-9 were measured using MMP activity assay systems (GE Healthcare Bio-Science K.K., Tokyo, Japan) according to the manufacturer's protocol. Culture media were incubated in the wells of plates precoated with primary antibodies. Enzyme-linked antibodies specific to each target were added, the plates were washed, and chromogenic substrate was added. The amount of color generated was measured at $405 \mathrm{~nm}$ using a microplate reader (Bio-Rad Laboratories, Hercules, Calif., USA).

\section{Immunocytochemistry}

A549 cells $\left(1 \times 10^{4} /\right.$ well $)$ were seeded onto Lab-TeK ${ }^{\circledR}$ chamber slides (Sigma-Aldrich, St. Louis, Mo., USA) and maintained until they reached about $80 \%$ confluence. The cells were stimulated with $1 \mathrm{ng} / \mathrm{ml} \mathrm{TGF}-\beta 1$ for $24 \mathrm{~h}$ with or without DOXY as described above and then examined by immunocytochemistry using a Vectastain Universal Elite ABC Kit (Vector Laboratories, Burlingame, Calif., USA) with goat anti-human collagen type I polyclonal antibody (Abcam, Inc.) diluted 1:1,000 in F-12 medium.

\section{SDS-PAGE and Western Blotting}

A549 cells were incubated with or without several concentrations of DOXY from $1 \mathrm{~h}$ before stimulation with $1 \mathrm{ng} / \mathrm{ml}$ TGF- $\beta 1$ until the end of the study. The cells were scraped and lysed in cell lysis buffer (Cell Signaling Technology, Danvers, Mass., USA) containing a protease inhibitor cocktail (Nacalai Tesque, Inc., Kyoto, Japan) at $60 \mathrm{~min}$ after TGF- $\beta 1$ stimulation. The lysates were centrifuged at $14,000 \mathrm{~g}$ for $10 \mathrm{~min}$ at $4^{\circ} \mathrm{C}$. Proteins were separated using $12 \%$ reducing SDS-PAGE and transferred to a polyvinylidene difluoride membrane (Bio-Rad) in 20\% methanol/25 $\mathrm{mM}$ Tris- $\mathrm{HCl} / 0.2 \mathrm{M}$ glycine. Nonspecific binding was blocked by incubating the membranes with 5\% skimmed milk in Tris buffer saline with $0.1 \%$ Tween 20 for $1 \mathrm{~h}$ at room temperature. Immunoreactive proteins were detected by incubating the membranes with rabbit anti-human Smad2 and Smad3, and phospho-Smad2 and phospho-Smad3 antibodies (Cell Signaling Technology) and GAPDH (Santa Cruz Biotechnology, Inc.) diluted at 1:500, 1:250, and 1:1,000, respectively, overnight at $4^{\circ} \mathrm{C}$. Subsequently, the membranes were incubated for $1 \mathrm{~h}$ with anti-rabbit IgG conjugated to HRP (1:10,000), washed, and then developed using enhanced chemiluminescence reagents (GE Healthcare, Little Chalfont, UK). Western blot images were scanned and analyzed using $\mathrm{NIH}$ Image J software. Results were expressed as a ratio of the band density of phospho-Smad to the respective total Smad.

\section{Statistical Analysis}

Data were statistically analyzed by an unpaired test for pairwise comparisons and by ANOVA followed by Dunnett's post hoc test for multiple comparisons using StatView J5.0 (SAS Institute, Inc., Cary, N.C., USA). All results are presented as the means \pm SD of at least 3 independent experiments. $p<0.05$ was considered statistically significant.

\section{Results}

\section{Effect of DOXY on Histological Findings in the BL-Induced Fibrosis Model}

A histological evaluation revealed no significant changes in the lungs of the control group at 14, 42, and 56 days (fig. 1a, b, c, respectively), whereas interstitial fibrosis was obvious in the lungs of the BL group (fig. 1d, e, f, respectively) and fibrotic areas in the lungs of the preDOXY group were reduced (fig. 1g, h, i, respectively) compared with the BL groups. Fibrotic areas were also reduced in the lungs of the post-DOXY group at 42 and 56 days (not shown). The mean fibrosis scores in the $\mathrm{BL}$ 


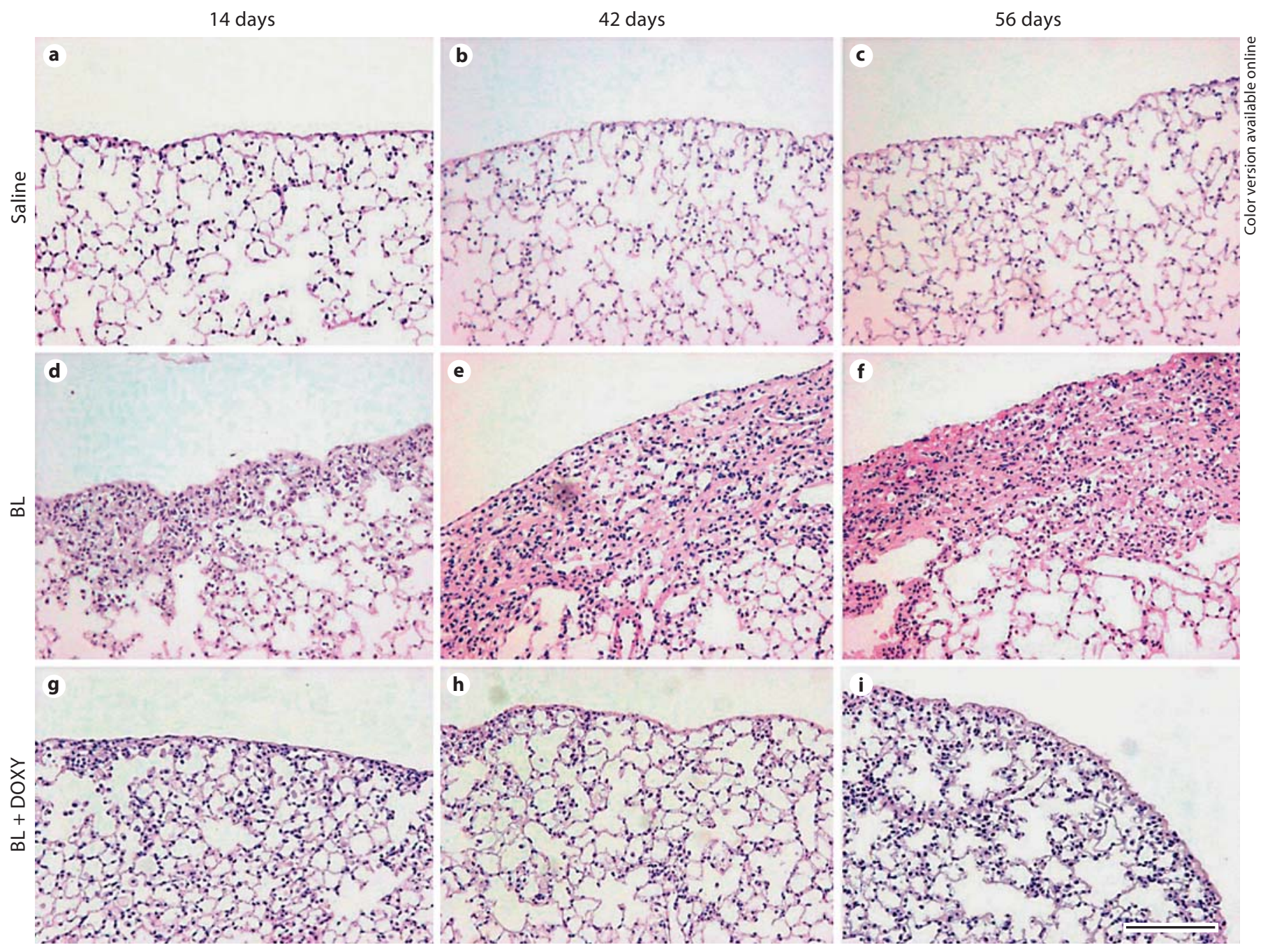

Fig. 1. Representative photographs of lungs from each group at various times (HE stain). At days 14, 42, and 56 interstitial fibrosis is evident in lungs from the $\mathrm{BL}$ group (d, e, f, respectively) compared with control lungs (a, $\mathbf{b}, \mathbf{c}$, respectively), and fibrotic areas are obviously reduced in lungs of the pre-DOXY group ( $\mathbf{g}, \mathbf{h}, \mathbf{i}$, respectively) relative to those of BL groups at corresponding times. Scale bar $=200 \mu \mathrm{m}$.

group at 14,42 , and 56 days $(4.80 \pm 1.61,2.33 \pm 0.59$, and $3.28 \pm 0.56$, respectively) were significantly higher than those in the control group $(1.05 \pm 0.09,1.11 \pm 0.31$, and $0.83 \pm 0.18$, respectively; fig. 2 ). Furthermore, prior incubation with DOXY significantly reduced the mean fibrosis scores at 14,42 , and 56 days $(3.01 \pm 0.35,1.48 \pm$ 0.34 , and $1.99 \pm 0.43$, respectively; fig. 2). Post-DOXY also inhibited the score $(2.08 \pm 0.70$; fig. 2$)$ at 56 days compared with the BL group.

\section{Effect of DOXY on Lung Hydroxyproline Content in} the BL-Induced Fibrosis Model

Figure 3 shows the effect of DOXY on the hydroxyproline content in the right lungs of mice at various times. The hydroxyproline contents were increased by BL at day 14 compared with the control group (195.2 \pm 31.8 vs. $148.8 \pm 11.0 \mu \mathrm{g} / \mathrm{lung}$ ) and DOXY significantly reduced the level increased by BL (147.0 $\pm 13.2 \mu \mathrm{g} / \mathrm{lung})$. The hydroxyproline levels induced by $\mathrm{BL}$ at 56 days were also significantly elevated and the increase was similarly diminished by pre- and post-DOXY. 


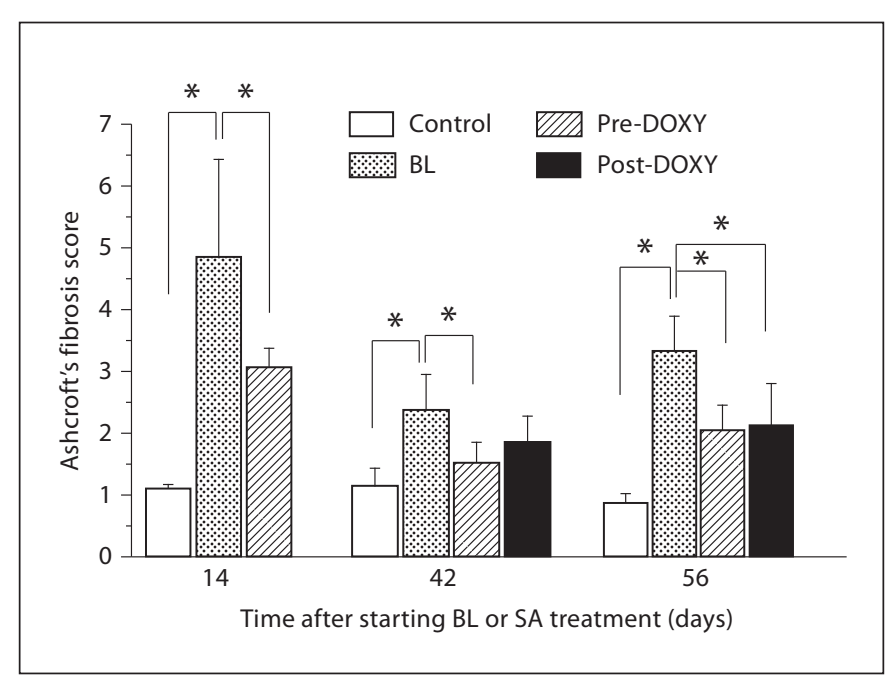

Fig. 2. Effects of DOXY on the fibrosis scores of the BL-induced fibrosis model at various times. Pre-DOXY incubation reduced the Ashcroft scores of the BL-induced fibrosis model at days 14, 42 , and 56 compared with the BL group. Post-DOXY incubation also reduced this score at 56 days compared with the BL group. The results are expressed as the mean \pm SD of data from 3-5 animals. ${ }^{*} \mathrm{p}<0.05$ compared with other groups at corresponding times.

\section{Effect of DOXY on the Immunohistochemical}

Expression of Fibrotic Mediators in a Model of

BL-Induced Fibrosis

Figure 4 shows representative immunohistochemically stained mediators in the model of BL-induced fibrosis. Compared with the control group (fig. $4 \mathrm{a}, \mathrm{b}, \mathrm{c}$, respectively), the immunoreactivity of TGF- $\beta 1$ (fig. $4 \mathrm{~d}$ ) was increased mainly in macrophages and AECs, and numbers of CTGF-positive cells (fig. 4e) were obviously increased among enlarged type II AECs and fibroblasts in the active fibrotic area in the BL group. The amount of collagen type I (fig. 4f) at ECM was also obviously increased. DOXY reduced the number of cells that were positive for TGF- $\beta 1$ (fig. 4g), CTGF (fig. 4h), and collagen type I (fig. 4i) in the fibrotic area in the pre-DOXY group. On the other hand, PDGF-A and PDGF-B were mainly stained in macrophages that accumulated in the active fibrotic area of the BL model but not in AECs, and DOXY reduced macrophage immunoreactivity (data not shown). Macrophages and AECs in the BL group were stained for MMP-2 compared with controls, and MMP-2 immunoreactivity was slightly decreased in the pre-DOXY group (data not shown). Macrophages in the BL group were mainly stained for MMP-9, whereas MMP-9 immunoreactivity in the pre-DOXY group did not change (data not shown).

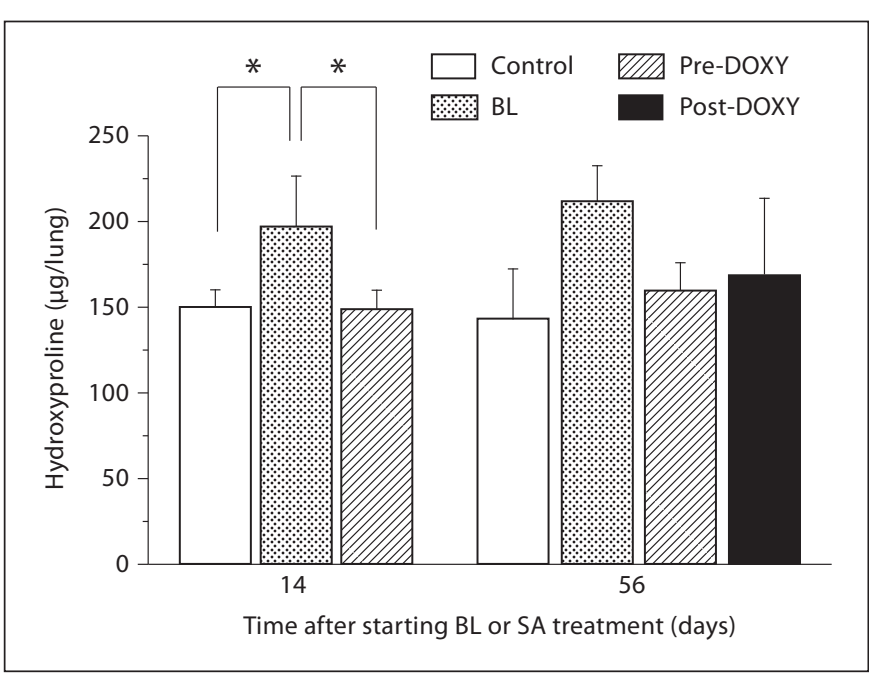

Fig. 3. Effects of DOXY on hydroxyproline content in the BL-induced fibrosis model at various times. Incubation with DOXY at day 14 significantly reduced hydroxyproline levels relative to corresponding values of the BL-treated group. A similar tendency at day 56 did not reach significance. The results are expressed as the means \pm SD of data from 3-5 animals. ${ }^{*} \mathrm{p}<0.05$ compared with other groups at corresponding time intervals.

\section{Effect of DOXY on Growth Factor mRNA Expression} and ECM Components Induced by TGF- $\beta 1$ in AECs

We assessed the production of TGF- $\beta 1$-induced profibrotic factors in the alveolar epithelial cell line A549 in vitro to determine how DOXY inhibits pulmonary fibrosis in the BL model. A preliminary experiment showed that stimulation with TGF- $\beta 1(1 \mathrm{ng} / \mathrm{ml}$ for $3 \mathrm{~h})$ significantly upregulated the mRNA expression of PDGF-A, CTGF, collagen type I, MMP-2, and MMP-9 and inhibited that of PDGF-B but did not affect that of HGF. Based on these findings, we examined the effect of DOXY on the expression of profibrotic factors stimulated with $1 \mathrm{ng} /$ $\mathrm{ml}$ of TGF- $\beta 1$ for $3 \mathrm{~h}$ in A549 cells. The mRNA expression of PDGF-A, CTGF, collagen type I, MMP-2, and MMP-9 induced by TGF- $\beta 1$ (fig. 5) was attenuated by DOXY at 15 or $30 \mu \mathrm{g} / \mathrm{ml}$. Furthermore, DOXY upregulated the expression of PDGF-B that was downregulated by TGF- $\beta 1$, but it had no effect on HGF expression.

\section{DOXY Attenuated the Protein Production of PDGF-AA, Active MMP-2, and Collagen Type I in $A E C$}

The secretion of PDGF-AA (fig. 6a) and active MMP-2 (fig. $6 \mathrm{~b}$ ) induced by TGF- $\beta 1$ was attenuated by DOXY. However, DOXY did not significantly affect PDGF-AB, 

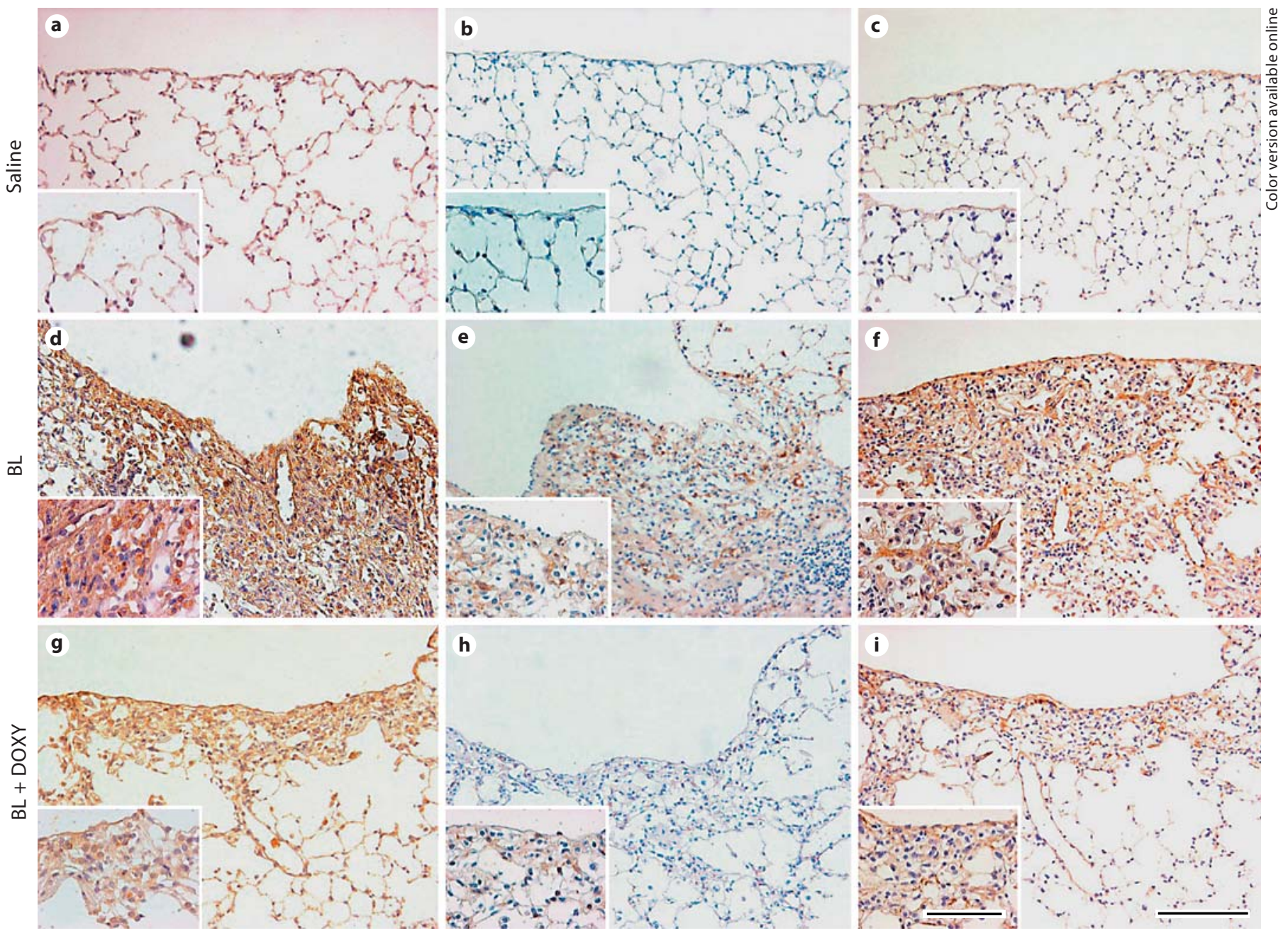

Fig. 4. Immunohistochemical evaluation of control, BL, and preDOXY groups at day 56. Type-II AECs and macrophages are positive for TGF- $\beta 1$ (a) and type-II AECs are positive for CTGF (b). Collagen type I is essentially undetectable (c) in control lung. Proliferative, TGF- $\beta 1$-positive cells (d), and CTGF-positive cells (e) in the active fibrotic area and collagen type I-positive ECM (f) are increased in lungs from the BL group. Numbers of TGF- $\beta 1$-positive cells (g) and CTGF-positive cells (h) as well as collagen type I production (i) are reduced in pre- and post-DOXY groups (not shown). Scale bars $=200(\mathbf{a}-\mathbf{i})$ and $100 \mu \mathrm{m}$ (insets).
PDGF-BB, HGF, and MMP-9 production (data not shown) and CTGF was undetectable by ELISA in the supernatant. The production of collagen type I enhanced by $1 \mathrm{ng} / \mathrm{ml}$ TGF- $\beta 1$ (fig. 6d) in A549 cells at $24 \mathrm{~h}$ compared with the control (fig. 6c) was attenuated by DOXY (fig. 6e).

\section{Effect of DOXY on TGF- $\beta 1$-Induced Smad Signaling Pathway}

The phosphorylation of Smad 2 and Smad 3 was examined in A549 cells at 60 min after stimulation with TGF$\beta 1(1 \mathrm{ng} / \mathrm{ml})$. TGF- $\beta 1$ induced the phosphorylation of both Smad2 and Smad3 without affecting the expression of total Smad2 and Smad3 (fig. 7a, b). DOXY did not affect the TGF- 31 -mediated phosphorylation of $\operatorname{Smad} 2$ and Smad3.

\section{Effect of TGF- $\beta 1$ and DOXY on Fibroblasts}

We evaluated the effect of DOXY in vitro on fibroblasts, another important target of therapy for IPF. The mRNA expression of CTGF and collagen type I was upregulated in fibroblasts $48 \mathrm{~h}$ after TGF- $\beta 1(5 \mathrm{ng} / \mathrm{ml})$ administration. The mRNA expression of MMP-2 and 


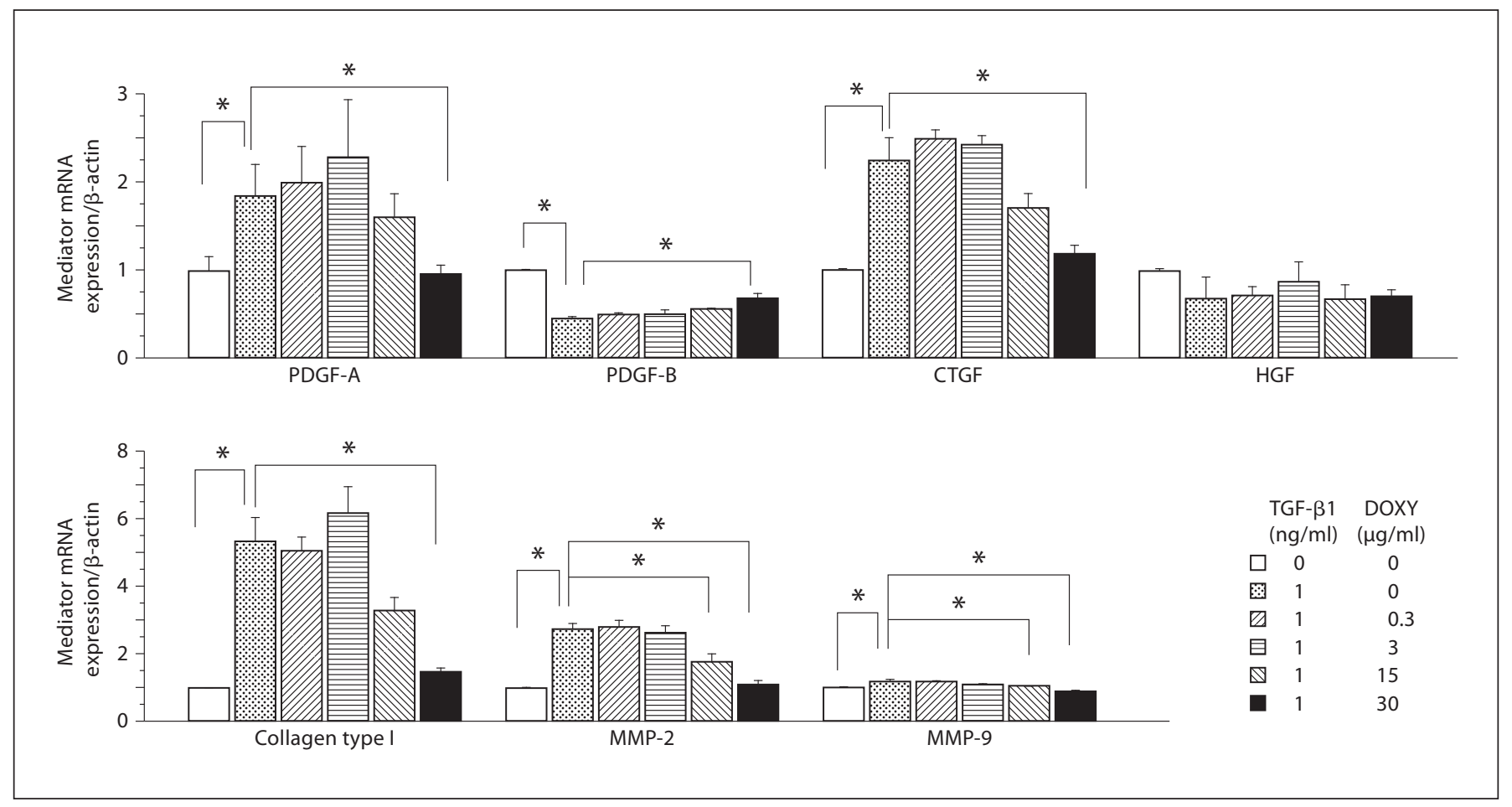

Fig. 5. Effects of DOXY on the mRNA expression of growth factors, collagen type I, and MMPs induced by TGF- $\beta 1$ in A549 cells. DOXY attenuated the TGF- $\beta 1$-induced mRNA expression of PDGF-A, CTGF, collagen type I, MMP-2, and MMP-9, but it recovered the PDGF-B mRNA expression inhibited by TGF- $\beta 1$. Data are presented as means \pm SD. ${ }^{*} \mathrm{p}<0.05$ compared with expression after 3 h of TGF- $\beta 1$ stimulation.

MMP-9 as well as HGF was not affected by TGF- $\beta 1$, and neither PDGF-A nor PDGF-B was detectable in fibroblasts. Various concentrations of DOXY up to $30 \mu \mathrm{g} / \mathrm{ml}$ did not affect the CTGF and collagen type I mRNA expression induced by TGF- $\beta 1$ (data not shown).

\section{Discussion}

The present study demonstrated that DOXY attenuated BL-induced pulmonary fibrosis. The production of TGF- $\beta 1$-induced mediators that are considered to play important roles in the progression of pulmonary fibrosis was also attenuated by DOXY in AECs in vitro. Considering that multiple cycles of epithelial cell damage and activation might cause IPF, AECs are considered to play various roles including provoking the migration, proliferation, and activation of mesenchymal cells along with the formation of fibroblastic/myofibroblastic foci and excessive ECM accumulation, thus mirroring abnormal wound repair [2].
Here, we focused on the effect of DOXY on AECs that release various types of growth factors and ECM components that can induce the profibrotic role of fibroblasts as described above and conclusively contribute to the progression of pulmonary fibrosis [2]. Among these, PDGF, CTGF, HGF, and MMPs are considered to play major roles in pulmonary fibrosis. The present study showed that DOXY attenuated the TGF- $\beta 1$-induced mRNA expression of PDGF-A, CTGF, MMP-2, and MMP-9 as well as the protein production of PGDF-AA and MMP-2 in AECs in vitro. We also showed that DOXY reduced the protein production of CTGF in AECs in vivo.

The potent mitogen PDGF is also a chemoattractant factor for mesenchymal cells and it has profibrotic activities [16]. The dimeric isoforms PDGF-A and PDGF-B are upregulated in AECs and in bronchoalveolar lavage fluid from the lungs of patients with IPF $[17,18]$. Although its role is now debatable, the PDGF/PDGF receptor system remains a promising target for treating fibrotic diseases [19]. Although we did not identify PDGF expression in AECs in our BL model and the reason for the 


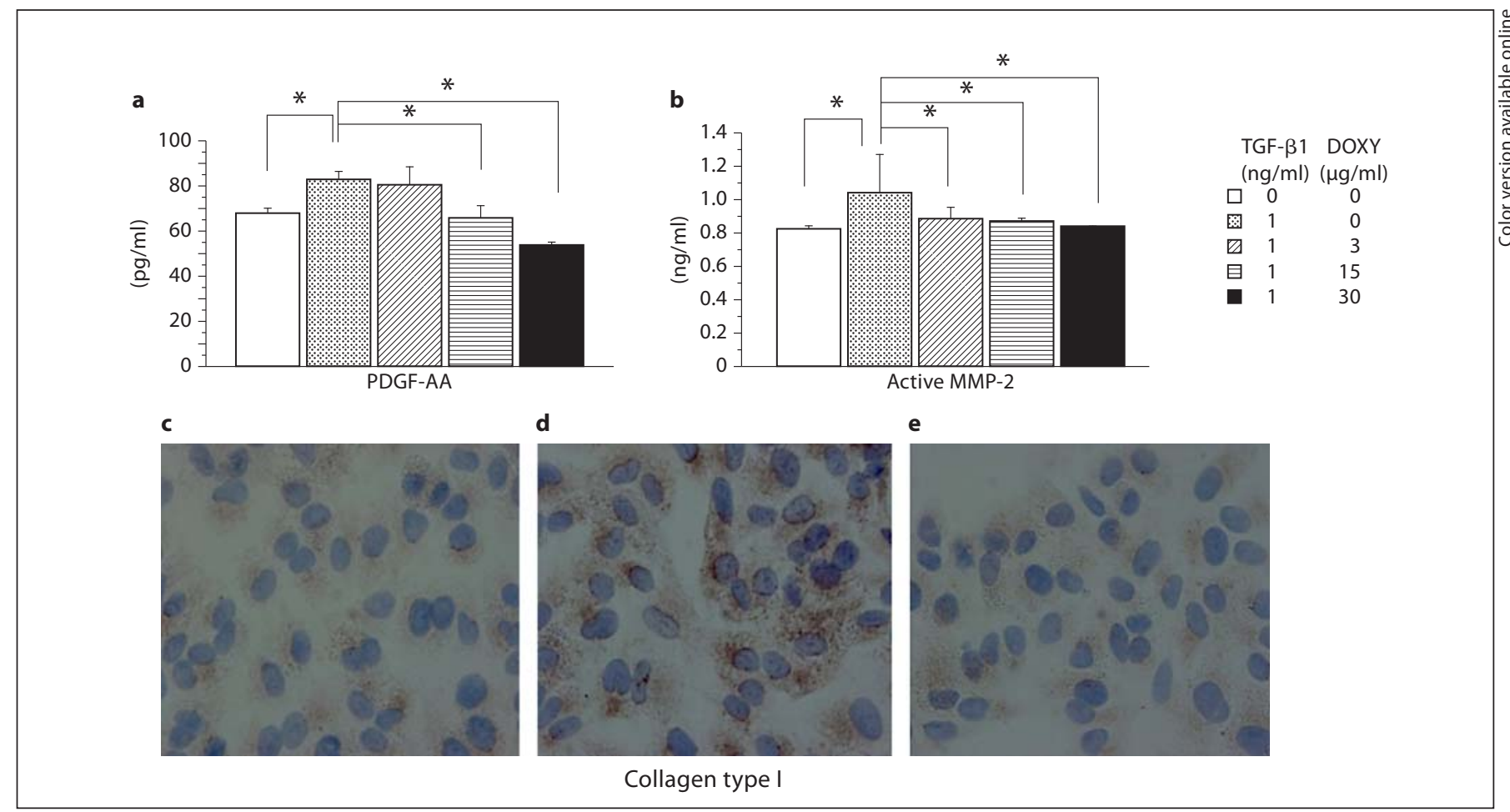

Fig. 6. Effects of DOXY on the production of PDGF-AA, collagen type I, and active MMP-2 induced by TGF- $\beta 1$ in A549 cells. ELISA and MMP activity assays show that DOXY attenuated the production of PDGF-AA (a) and active MMP-2 (b) induced by TGF$\beta 1$ in the supernatant. DOXY attenuated the production of col- lagen type I enhanced by $1 \mathrm{ng} / \mathrm{ml}$ TGF- $\beta 1$ (d) in A549 cells at $24 \mathrm{~h}$ compared with the control (c, e) (immunocytochemical staining). Data are shown as means \pm SD. ${ }^{*} \mathrm{p}<0.05$ compared with expression after TGF- $\beta 1$ stimulation. a

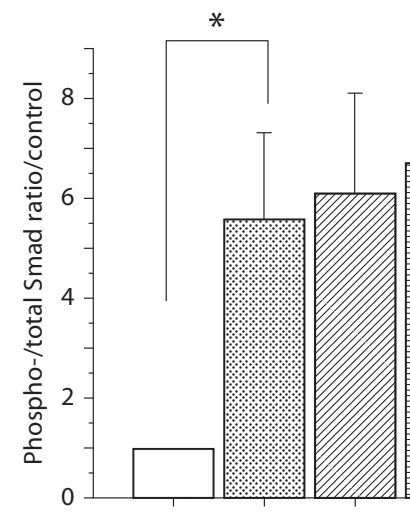

p-Smad 2

$\mathrm{t}-\mathrm{Smad} 2$

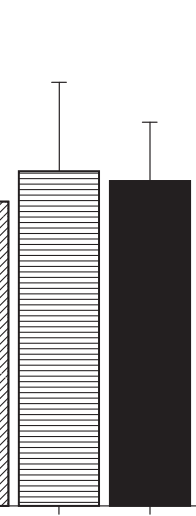

$-60 \mathrm{kDa}$

$-60 \mathrm{kDa}$ b

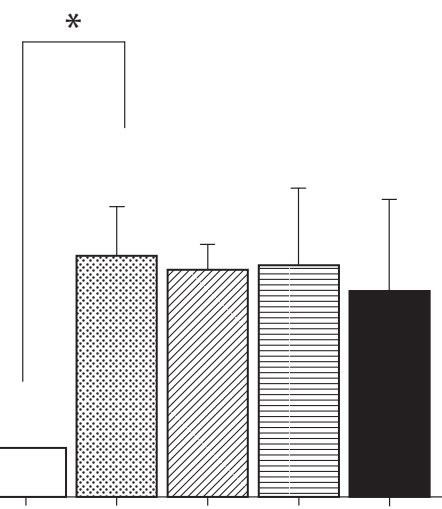

p-Smad 3

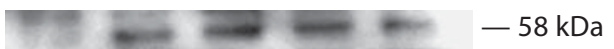

t-Smad 3

$-58 \mathrm{kDa}$
Fig. 7. Effects of DOXY on the TGF- $\beta 1$-induced Smad signaling pathway. TGF- $\beta 1$ induced the expression of phospho-Smad2 (a) and phospho-Smad3 (b) but did not affect the total Smad2 and
Smad3 values. DOXY did not affect Smad 2 and Smad3 phosphorylation. Data are presented as means $\pm \mathrm{SD} .{ }^{*} \mathrm{p}<0.05$. 
different responses of PDGF-A and PDGF-B to both TGF- $\beta 1$ and DOXY remains unknown, our findings suggests that DOXY attenuates lung fibrosis by reducing PDGF expression from AECs.

Furthermore, CTGF is considered to act in concert with TGF- $\beta 1$ downstream and to play a significant role in promoting and maintaining fibrogenesis induced by proliferating AECs and activated fibroblasts in IPF [20]. Thus, CTGF is also a target in IPF and a CTGF-specific antibody has been tested in a clinical trial of patients with IPF [1]. Our present findings that DOXY attenuated CTGF production in the BL-model and TGF- $\beta$-induced CTGF expression in AECs suggest that DOXY could attenuate pulmonary fibrosis by inhibiting CTGF production from AECs.

We also showed that DOXY in AECs affected the production of MMP-2 and MMP-9, which play roles in cell proliferation, adhesion, migration, and differentiation through proteolytic effects on ECM components and basement membranes that contribute to the progression of fibrosis [21]. The gene and protein expression of MMP2 and MMP-9 is elevated in tissues and in bronchoalveolar lavage fluid from patients with IPF [22]. Fujita et al. [12] demonstrated that DOXY decreases the production and activity of the MMP-9 protein but not the expression of MMP-9 mRNA from inflammatory cells in BAL fluid from a model of BL-induced pulmonary fibrosis. In addition, the synthetic MMP inhibitor batimastat prevents BL-induced pulmonary fibrosis by reducing MMP-2 and MMP-9 activity [23]. These reports indicate that MMP is a potential therapeutic target of pulmonary fibrosis. Although our results in vivo did not uncover a significant association between MMP inhibition and pulmonary fibrosis, our in vitro study indicates that DOXY reduces pulmonary fibrosis by not only inhibiting MMPs activity but also reducing the production of MMP-2 induced by TGF- $\beta 1$ from AECs.

The origin of the expanded populations of lung fibroblasts and myofibroblasts in lungs with pulmonary fibrosis is of substantial interest. Reports indicate that AECs can serve as progenitor cells that can undergo differentiation to fibroblasts/myofibroblasts in response to TGF$\beta$ with the generation of ECM $[3,4]$. The process is called EMT. In this process epithelial cells lose cell-cell attachment, polarity, and epithelial-specific markers, and they undergo cytoskeletal remodeling and acquire a mesenchymal phenotype [24]. EMT can occur in the lungs and contribute to fibrosis in patients with IPF [25]. Mediators such as collagen type I, CTGF, and MMP-2 that are downregulated by DOXY in AECs are also considered to be markers of EMT $[3,26]$. These results indicate that DOXY attenuates the production of TGF- $\beta$-induced mediators by inhibiting EMT. TGF- $\beta$-mediated EMT is considered to be partly dependent on Smad 2 and Smad3 phosphorylation $[3,26]$. Activated Smads mediate transcriptional regulation through other families of transcription factors resulting in the activation of mesenchymal gene expression including MMPs and collagen [27]. DOXY did not reduce TGF- $\beta$-induced Smad phosphorylation in the present study. Activation of the Ras-Erk MAP kinase pathway, p38 MAP kinase and JNK signaling, as well as Rho GTPase signaling and the PI3 kinase/Akt pathway also contribute to TGF- $\beta$-induced EMT [27]. DOXY inhibits the TGF- $\beta$-induced activation of Smad2, JNK, ERK, and p38 MAP kinases in human corneal epithelial cells [28]. DOXY also decreases p38 MAP kinase in the TNF- $\alpha$-, IL-1 $\beta$-, and IFN- $\gamma$-treated murine lung alveolar epithelial cell line LA4 [6]. Although further studies are required, our findings indicated that DOXY attenuates the production of TGF- $\beta$-induced mediators in alveolar epithelial cells via a non-Smad pathway.

We also examined the effect of DOXY in lung fibroblasts in vitro. We could not assess the effect of DOXY on the expression of mediators (PDGF-A, PDGF-B, HGF, MMP-2, and MMP-9) in fibroblasts because TGF- $\beta 1$ stimulation did not affect their expression. The RNA expression of CTGF and collagen type I upregulated by TGF- $\beta 1$ stimulation was not affected by DOXY. We investigated the effect of DOXY in lung fibroblasts in plastic dishes in vitro, and others have reported the influence of collagen type I on fibroblast function and the effect of MMP inhibitors such as DOXY $[29,30]$. The presence of collagen type I in the medium might affect the present results.

Although one limitation of this study is that only A549 cells and primary human lung fibroblasts were investigated, the inhibitory effect of DOXY on pulmonary fibrosis might be partly explained as a reduced production of profibrotic factors from AECs but not from lung fibroblasts.

We used TGF- $\beta 1$ to stimulate AECs and lung fibroblasts in vitro. TGF- $\beta 1$ plays the most pivotal role in the development and progress of fibrosis. The present study showed that DOXY reduced TGF- $\beta 1$ expression in a model of pulmonary fibrosis induced by BL. Although the precise mechanism of the reduced TGF- $\beta 1$ expression in BL-induced pulmonary fibrosis remains unknown, our results in vitro and in vivo suggest that DOXY attenuates pulmonary fibrosis by reducing both TGF- $\beta 1$ production and the TGF- $\beta 1$-induced fibrotic response. 
Additionally, DOXY attenuated fibrosis in both pre- and post-treatment groups in vivo. One study found that BLinduced pulmonary fibrosis is attenuated by earlier, but not by later, DOXY administration, which is somewhat controversial. Although the 2 studies are similar, the species of mouse and the period of $\mathrm{BL}$ administration differ. The most obvious difference is in the administration routes of $\mathrm{BL}$, which were intratracheally in the previous report and intravenously in the present study. Intratracheal BL reportedly induces lung fibrosis by day 14, whereas intravenous administration induces fibrosis more slowly [31]. These factors might explain the different results. DOXY inhibits not only inflammation during the earlier phase but also fibrosis at the later phase of pulmonary fibrosis.

Advances in elucidating disease pathogeneses and identifying new targets for treating IPF have recently led to several clinical trials of many agents. However, none has unequivocally yielded a survival benefit. Conse- quently, the search for safe and effective agents for treating IPF continues [32]. The therapeutic mechanisms of DOXY remain unknown, and evidence of its effectiveness in patients with IPF is inadequate. On the other hand, prolonged therapy with DOXY is well tolerated for several months under various conditions [13]. This could be favorable for treating IPF. Our data support the notion that DOXY could become a therapeutic option for the treatment of IPF.

In conclusion, DOXY appears to attenuate pulmonary fibrosis through the inhibition of growth factors and MMP production in AECs.

\section{Acknowledgment}

The authors thank Mr. Atsushi Yokoyama (Nagasaki University Hospital) for his excellent technical support.

\section{References}

1 du Bois RM: Strategies for treating idiopathic pulmonary fibrosis. Nat Rev Drug Discov 2010;9:129-140.

2 Selman M, Pardo A: Role of epithelial cells in idiopathic pulmonary fibrosis: from innocent targets to serial killers. Proc Am Thorac Soc 2006;3:364-372.

- 3 Kasai H, Allen JT, Mason RM, Kamimura T, Zhang Z: TGF-beta1 induces human alveolar epithelial to mesenchymal cell transition (EMT). Respir Res 2005;6:56.

4 Willis BC, Liebler JM, Luby-Phelps K, Nicholson AG, Crandall ED, du Bois RM, Borok $\mathrm{Z}$ : Induction of epithelial-mesenchymal transition in alveolar epithelial cells by transforming growth factor-betal: potential role in idiopathic pulmonary fibrosis. Am J Pathol 2005;166:1321-1332.

5 Raza M, Ballering JG, Hayden JM, Robbins RA, Hoyt JC: Doxycycline decreases monocyte chemoattractant protein-1 in human lung epithelial cells. Exp Lung Res 2006;32: $15-26$.

6 Hoyt JC, Ballering J, Numanami H, Hayden JM, Robbins RA: Doxycycline modulates nitric oxide production in murine lung epithelial cells. J Immunol 2006;176:567-572.

$\checkmark 7$ Iwasaki H, Inoue H, Mitsuke Y, Badran A, Ikegaya S, Ueda T: Doxycycline induces apoptosis by way of caspase-3 activation with inhibition of matrix metalloproteinase in human T-lymphoblastic leukemia CCRFCEM cells. J Lab Clin Med 2002;140:382386.
-8 Curci JA, Mao D, Bohner DG, Allen BT, Rubin BG, Reilly JM, Sicard GA, Thompson RW: Preoperative treatment with doxycycline reduces aortic wall expression and activation of matrix metalloproteinases in patients with abdominal aortic aneurysms. J Vasc Surg 2000;31:325-342.

-9 Almazin SM, Dziak R, Andreana S, Ciancio SG: The effect of doxycycline hyclate, chlorhexidine gluconate, and minocycline hydrochloride on osteoblastic proliferation and differentiation in vitro. J Periodontol 2009;80:999-1005.

10 Lokeshwar BL, Selzer MG, Zhu BQ, Block NL, Golub LM: Inhibition of cell proliferation, invasion, tumor growth and metastasis by an oral non-antimicrobial tetracycline analog (COL-3) in a metastatic prostate cancer model. Int J Cancer 2002;98:297-309.

11 Gueders MM, Bertholet P, Perin F, Rocks N, Maree R, Botta V, Louis R, Foidart JM, Noel A, Evrard B, Cataldo DD: A novel formulation of inhaled doxycycline reduces allergeninduced inflammation, hyperresponsiveness and remodeling by matrix metalloproteinases and cytokines modulation in a mouse model of asthma. Biochem Pharmacol 2008;75:514-526.

12 Fujita M, Ye Q, Ouchi H, Harada E, Inoshima I, Kuwano K, Nakanishi Y: Doxycycline attenuated pulmonary fibrosis induced by bleomycin in mice. Antimicrob Agents Chemother 2006;50:739-743.
13 Bhattacharyya P, Nag S, Bardhan S, Acharya D, Paul R, Dey R, Ghosh M, Saha I: The role of long-term doxycycline in patients of idiopathic pulmonary fibrosis: the results of an open prospective trial. Lung India 2009;26: 81-85.

14 Kakugawa T, Mukae H, Hayashi T, Ishii H, Abe K, Fujii T, Oku H, Miyazaki M, Kadota J, Kohno S: Pirfenidone attenuates expression of HSP47 in murine bleomycin-induced pulmonary fibrosis. Eur Respir J 2004;24: 57-65.

15 Ashcroft T, Simpson JM, Timbrell V: Simple method of estimating severity of pulmonary fibrosis on a numerical scale. J Clin Pathol 1988;41:467-470.

16 Betsholtz C: Biology of platelet-derived growth factors in development. Birth Defects Res C Embryo Today 2003;69:272-285.

17 Cao B, Guo Z, Zhu Y, Xu W: The potential role of PDGF, IGF-1, TGF-beta expression in idiopathic pulmonary fibrosis. Chin Med J (Engl) 2000;113:776-782.

18 Homma S, Nagaoka I, Abe H, Takahashi K, Seyama K, Nukiwa T, Kira S: Localization of platelet-derived growth factor and insulinlike growth factor I in the fibrotic lung. Am J Respir Crit Care Med 1995;152:2084-2089.

19 Abdollahi A, Li M, Ping G, Plathow C, Domhan S, Kiessling F, Lee LB, McMahon G, Grone HJ, Lipson KE, Huber PE: Inhibition of platelet-derived growth factor signaling attenuates pulmonary fibrosis. J Exp Med 2005;201:925-935. 
20 Allen JT, Knight RA, Bloor CA, Spiteri MA: Enhanced insulin-like growth factor binding protein-related protein 2 (connective tissue growth factor) expression in patients with idiopathic pulmonary fibrosis and pulmonary sarcoidosis. Am J Respir Cell Mol Biol 1999;21:693-700.

21 Pardo A, Selman M: Matrix metalloproteases in aberrant fibrotic tissue remodeling. Proc Am Thorac Soc 2006;3:383-388.

-22 Selman M, Ruiz V, Cabrera S, Segura L, Ramirez R, Barrios R, Pardo A: TIMP-1, -2, -3 , and -4 in idiopathic pulmonary fibrosis: a prevailing nondegradative lung microenvironment? Am J Physiol Lung Cell Mol Physiol 2000;279:L562-L574.

-23 Corbel M, Caulet-Maugendre S, Germain N, Molet S, Lagente V, Boichot E: Inhibition of bleomycin-induced pulmonary fibrosis in mice by the matrix metalloproteinase inhibitor batimastat. J Pathol 2001;193:538-545.

-24 Willis BC, du Bois RM, Borok Z: Epithelial origin of myofibroblasts during fibrosis in the lung. Proc Am Thorac Soc 2006;3:377382.
25 Kim KK, Kugler MC, Wolters PJ, Robillard L, Galvez MG, Brumwell AN, Sheppard D, Chapman HA: Alveolar epithelial cell mesenchymal transition develops in vivo during pulmonary fibrosis and is regulated by the extracellular matrix. Proc Natl Acad Sci USA 2006;103:13180-13185.

26 Tan X, Dagher H, Hutton CA, Bourke JE: Effects of PPAR gamma ligands on TGF-beta1induced epithelial-mesenchymal transition in alveolar epithelial cells. Respir Res 2010; 11:21.

27 Xu J, Lamouille S, Derynck R: TGF-beta-induced epithelial to mesenchymal transition. Cell Res 2009;19:156-172.

28 Kim HS, Luo L, Pflugfelder SC, Li DQ: Doxycycline inhibits TGF-betal-induced MMP-9 via Smad and MAPK pathways in human corneal epithelial cells. Invest Ophthalmol Vis Sci 2005;46:840-848.
29 Xia H, Diebold D, Nho R, Perlman D, Kleidon J, Kahm J, Avdulov S, Peterson M, Nerva J, Bitterman P, Henke C: Pathological integrin signaling enhances proliferation of primary lung fibroblasts from patients with idiopathic pulmonary fibrosis. J Exp Med 2008;205:1659-1672.

30 Schuliga MJ, See I, Ong SC, Soon L, Camoretti-Mercado B, Harris T, Stewart AG: Fibrillar collagen clamps lung mesenchymal cells in a nonproliferative and noncontractile phenotype. Am J Respir Cell Mol Biol 2009;41:731741.

31 Moore BB, Hogaboam CM: Murine models of pulmonary fibrosis. Am J Physiol Lung Cell Mol Physiol 2008;294:L152-L160.

32 Thannickal VJ, Roman J: Challenges in translating preclinical studies to effective drug therapies in idiopathic pulmonary fibrosis. Am J Respir Crit Care Med 2010;181: 532-533. 